Servicio de Clínica Médica, 2Servicio de Hematología, ${ }^{3}$ Servicio de Histopatología, Hospital Británico de Buenos Aires, Argentina.

Conflictos de interés: Los autores declaran no tener conflictos de interés.

Recibido el 16 de enero de 2015, aceptado el 17 de junio de 2015.

Correspondencia a: Dr. Pablo Young.

Hospital Británico. Perdriel 74 (1280) Buenos Aires, Argentina.

Tel: 541143096400

Fax: 541143043393

pabloyoung2003@yahoo.com.ar

\section{Linfoma intravascular, un desafio diagnóstico. Caso clínico}

\author{
PABLO YOUNG ${ }^{1}$, MARÍA MASSA ${ }^{1}$, BÁRBARA C. FINN ${ }^{1}$, \\ GONZALO FLEIRE ${ }^{1}$, GERMÁN R. STEMMELIN ${ }^{2}$, AMANDA RUADES $^{2}$, \\ DANIEL SUTOVSKY ${ }^{2}$, JOSÉ G. CASAS ${ }^{3}$, PABLO DEZANZO $^{3}$, \\ FÉLIX VIGOVICH ${ }^{3}$, JULIO E. BRUETMAN ${ }^{1}$
}

\section{Intravascular lymphoma. Report of one case}

Intravascular lymphoma is a rare subtype of extranodal diffuse large B-cell lymphoma characterized by clonal proliferation of lymphocytes inside of small and medium caliber vessels. Its incidence is estimated at one case per million. The clinical picture is very variable, but frequently has skin and central nervous system involvement. It is diagnosed by demonstrating pathological blood vessel infiltration by lymphoma cells. We report a 44 years old male presenting with fever, malaise and erythematous lesions in the abdominal wall. An abdominal wall biopsy showed dilated vascular vessels with atypical cells in their lumen, compatible with large B-cell intravascular lymphoma. He was treated with rituximab, cyclophosphamide, adriamycin, vincristine and prednisone and an autologous hematopoietic stem cell transplantation, achieving a complete remission that has lasted two years.

(Rev Med Chile 2015; 143: 1076-1080)

Key words: Hematopoietic stem cell transplantation; Lymphoma, B-cell; Rituximab.
$\mathrm{E}$ 1 linfoma intravascular (LI) es un subtipo infrecuente de linfoma extranodal difuso de células grandes $\mathrm{B}^{1-3}$. Anatómicamente se caracteriza por una proliferación clonal de linfocitos dentro de vasos de pequeño y mediano calibre, particularmente capilares y vénulas post-capilares sin presentar masa tumoral extravascular o células atípicas en sangre periférica. Desde su descripción por Pfleger y Tappeiner en 1959, menos de 1.000 casos han sido reportados hasta la fecha ${ }^{4}$. Se presenta un caso de síndrome febril prolongado y compromiso cutáneo abdominal cuyo diagnóstico final fue un LI, realizando una revisión de la literatura.

\section{Caso clínico}

Hombre de 44 años de edad, oriundo de Salta capital, Argentina, profesor de escuela secundaria, con antecedentes de asma intermitente leve.
Comenzó dos meses previos a la derivación con astenia, adinamia, pérdida de peso involuntaria asociado a registros febriles diarios a predominio nocturnos acompañados de sudoración. Un mes previo a su ingreso al hospital fue internado en la provincia de Salta donde se realizaron numerosos estudios. En los análisis presentó velocidad de eritrosedimentación globular (VSG) $60 \mathrm{~mm}$ en la primera hora con un valor normal (VN) $<20$, proteína C reactiva (PCR) $4,8 \mathrm{mg} / \mathrm{dl}(\mathrm{VN}$ $<0,3$ ), glóbulos blancos 8.000 por $\mathrm{mm}^{3}$ con fórmula normal (normal $<10.000$ ), hematocrito de $26 \%$ (VN 40-45\%) (con valores compatibles con anemia normocítica normocrómica), plaquetas de $253.000 \mathrm{~mm}^{3}$, transaminasas normales, fosfatasa alcalina (FAL) de $899 \mathrm{U} / \mathrm{l}(\mathrm{VN}$ 38-126 U/l), gamaglutamiltranspeptidasa (GGT) de $291 \mathrm{UI} / 1$ (VN 0-51 UI/l), láctico-deshidrogenasa (LDH) de $1.424 \mathrm{U} / \mathrm{l}$ (VN 313-618 U/I), ferritina $2.708 \mathrm{ng} /$ $\mathrm{ml}$ (VN 30-400 ng/ml), albúmina de 1,5 g/dl (VN 
$3,5-5,5 \mathrm{~g} / \mathrm{dl}$ ) y función tiroidea normal. Resto fue normal incluyendo el sedimento de orina. Todos los marcadores serológicos virales fueron negativos incluyendo virus de la hepatitis A, hepatitis B, hepatitis C, citomegalovirus, Epstein Barr, y virus de la inmunodeficiencia humana. Otros marcadores como la VDRL, la reacción de Huddleson, la gota gruesa, y el test de Widal fueron negativos. La PPD fue negativa. Se realizaron tres pares de hemocultivos que fueron negativos para gérmenes comunes y brucelosis. La prueba de Coombs directa e indirecta fue negativa. Se realizó una ecografía abdominal, prostática y testicular que mostró esteatosis hepática, y resto sin particularidades. Una colangio resonancia magnética nuclear fue normal. El eco-Doppler color trans-esofágico no mostró vegetaciones. Una tomografía axial computada (TAC) de cerebro, tórax, abdomen y pelvis con contraste oral y endovenoso mostró

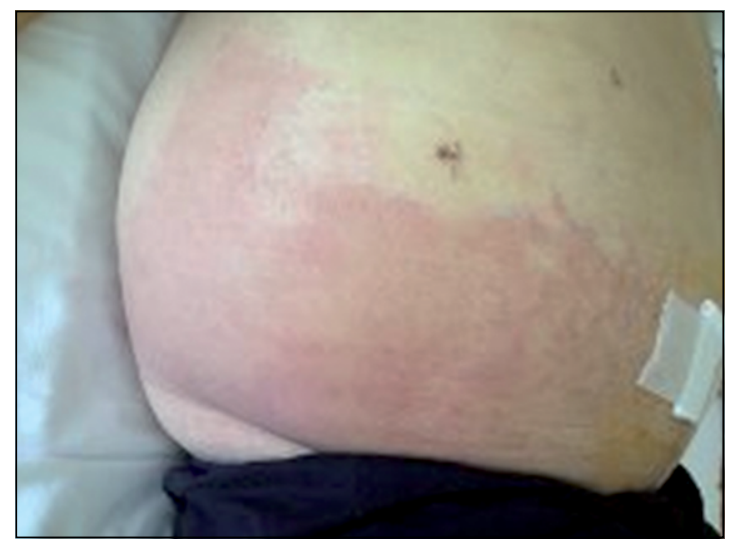

Figura 1. Eritema marmóreo en pared abdominal. importante edema subcutáneo de pared abdominal generalizado, y resto sin particularidades. Se realizaron endoscopías alta y baja sin hallazgos patológicos. A su vez la punción aspirado de médula ósea mostró celularidad normal y cultivos negativos. Dada la alteración de las pruebas hepáticas se realizó biopsia hepática y colecistectomía cuya anatomía patológica informó hepatitis focal leve inespecífica, esteatosis y colecistitis crónica inespecífica.

Por persistencia de registros febriles sin etiología clara, a los dos meses del comienzo del cuadro, es admitido en nuestra institución. Al ingreso se encontró persistentemente febril, y como único hallazgo al examen físico presentó edema indurado en región abdominal y eritema marmóreo (Figura 1). Se repiten cultivos, serologías y tomografías sin nuevos hallazgos. Se realizó punción de partes blandas de pared abdominal en el área de eritema donde se rescata Streptococcus multisensible por lo que recibió durante una semana tratamiento con amoxicilina sin objetivarse cambio clínico. Se instaló sonda nasogástrica para alimentación y se realizó soporte transfusional. El paciente persistió febril por lo que se tomó biopsia cutánea y de tejido celular subcutáneo. Esta informó hipodermis con estructuras vasculares dilatadas con presencia en su luz de células grandes atípicas con nucléolos prominentes CD 45+, CD 68-, CD 20+, PAX 5+, CD 79a+, CD 10-, CD 3-, CD 45 Ro-, CD 34-, mieloperoxidasa-, Ki 67 80\%, compatible con linfoma de células grandes B intravascular (Figura 2). Resonancia magnética nuclear (RNM) de cerebro con gadolinio no mostró alteraciones. Inició tratamiento con rituximab, ciclofosfamida, adriamicina, vincristina y prednisona ( $\mathrm{R}-\mathrm{CHOP})$

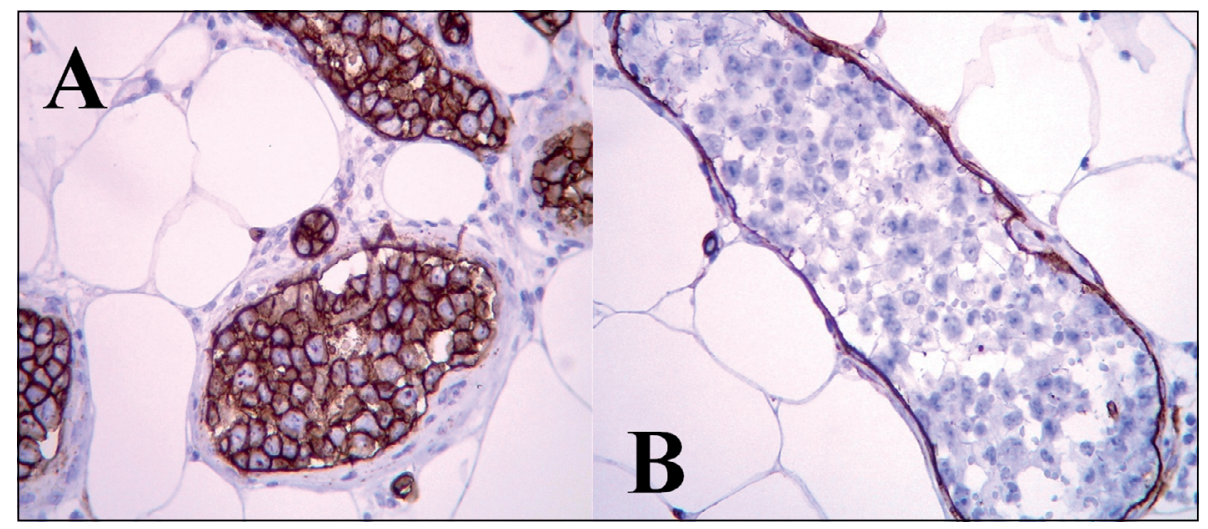

Figura 2. Hipodermis con estructuras vasculares dilatadas que contienen en su luz células grandes atípicas con nucléolos prominentes e inmunomarcación para: A) $\mathrm{CD} 20+\mathrm{y}$ en B) $\mathrm{CD} 34$ - 
cada 21 días por 6 aplicaciones. Presentó buena evolución, sin fiebre, disminución del edema abdominal y franca mejoría del estado general. Se realizó trasplante autólogo de células madres hematopoyéticas (TAMO) como consolidación de la primera remisión completa, y se encuentra libre de enfermedad desde hace dos años.

\section{Discusión}

El LI es un subtipo infrecuente de linfoma de células grandes B. Se define como una proliferación clonal intravascular de linfocitos sin compromiso del parénquima. Actualmente se utiliza el nombre de LI de células grandes B.

La incidencia se calcula en menos de una persona por millón. Fue descrita en pacientes con un rango de edad entre los 34 y los 90 años, con una edad media de 70 años. No hay diferencias entre hombre y mujer y se desconocen factores de riesgo ${ }^{2,3}$.

La clínica del LI es sumamente variable y depende del órgano afectado. Aunque se basa en una proliferación clonal de linfocitos, en menos de 7\% se observan adenopatías, hepatoesplenomegalia, masa tumoral extravascular o presencia de células malignas en sangre periférica. La localización intravascular se explica por el defecto o ausencia en los linfocitos de las moléculas de adhesión CD29 (beta 1 integrina) y CD54 (ICAM-1) $)^{5}$. Debido a la liberación de citoquinas se observan síntomas B (fiebre, pérdida de peso, sudoración nocturna) en la mayoría de los pacientes según las series $(55-85 \%)^{1-3}$.

En países occidentales, los síntomas más comunes son debidos al compromiso del SNC (39\%) y piel $(39 \%)$. En menor frecuencia se pueden comprometer médula ósea (32\%), bazo $(26 \%)$ e hígado $(26 \%)^{3-7}$. A su vez en países orientales, predomina la infiltración de médula ósea $(75 \%)$, bazo $(67 \%)$, e hígado (67\%) siendo infrecuente el compromiso neurológico $(27 \%)$ y cutáneo ${ }^{1}$. Cualquier órgano puede estar comprometido.

El compromiso cutáneo puede aparecer como lesiones únicas o múltiples. Pueden presentarse como lesiones maculo-papulares, nódulos, placas, úlceras, placas hiperpigmentadas, lesiones livedoides o "piel de naranja" y placas induradas similar a paniculitis ${ }^{8}$. Es importante el diagnóstico diferencial con celulitis, carcinoma escamoso, gangrena, vasculitis, o sarcoma de Kaposi. Los sitios preponderantes de presentación son la región proximal de extremidades, abdomen inferior como en nuestro paciente y áreas submamarias 9 .

El compromiso del SNC puede presentarse como déficit motor o sensitivo, alteración del sensorio, demencia rápidamente progresiva, convulsiones, disartria, ataxia, vértigo o alteración visual. Se recomienda realizar punción lumbar $(\mathrm{PL})$ y neuroimágenes para descartar el compromiso de SNC así como el tratamiento profiláctico en caso de ser negativa ${ }^{9,10}$. Dado que nuestro paciente no presentó síntomas de compromiso de SNC o imágenes compatibles, se decidió no realizar PL, ni tratamiento intratecal profiláctico.

El LI puede presentarse, como en nuestro caso, con fiebre de origen desconocido, que se observa de inicio en $45 \%$ de los $\operatorname{casos}^{9-12}$. Nuestro paciente presentó además síndrome de ocupación hepática, dado el incremento de FAL y GGT con transaminasas normales, por lo que se realizó biopsia hepática que fue negativa debido a la naturaleza parcheada de la enfermedad ${ }^{13,14}$.

Otras formas de presentación poco frecuentes incluyen insuficiencia suprarrenal, hipertensión pulmonar, síndrome nefrótico, infarto de miocardio y enfermedad pulmonar intesticial ${ }^{15,16}$.

Se observan LDH y beta 2-microglobulina aumentadas hasta en $80-90 \%$ de los casos, anemia en $65 \%$, así como incremento de la VSG en más de la mitad de los casos. Existe una marcada diferencia entre occidente y oriente (Asia) en cuanto a los valores de trombocitopenia (29 contra 76\%) e hipoalbuminemia (18 versus $84 \%)^{17,18}$.

La anatomía patológica de los tejidos afectados muestra infiltración por células neoplásicas linfoides de los capilares y vénulas post-capilares. Es infrecuente encontrar células malignas en LCR, sangre periférica o infiltración de medula ósea. La morfología celular es variable, frecuentemente se observan células linfoides grandes que presentan núcleo y nucléolo prominente. Se pueden ver abundantes figuras mitóticas ya que son de alta actividad proliferativa demostrada también por un ki67 elevado. El inmunofenotipo usualmente las identifica como células B maduras, considerándose una variante de linfoma difuso de células grandes $\mathrm{B}$, presentando los siguientes antígenos de superficie: CD19, CD20, CD22 y CD79. Existen casos infrecuentes donde se identifican células $\mathrm{T}$ o natural killers ${ }^{17}$. 
El diagnóstico se realiza mediante biopsia de tejido afectado. Es de máxima importancia que en el caso de compromiso cutáneo se tome una biopsia profunda incluyendo tejido celular subcutáneo, ya que los vasos afectados pueden estar ubicados preferentemente en la grasa subcutánea como en nuestro caso.

Existen casos de LI con TAC normal y tomografía por emisión de positrones (PET/TAC) positiva. No se realizó en nuestro paciente de comienzo ya que estaba muy comprometido y requirió inicio de corticoides. Si bien existen pocas comunicaciones, el PET/TAC puede marcar sitios de compromiso no evidentes en la TAC posibles de ser biopsiados ${ }^{5,14,16}$. Le realizamos PET/TAC pre-TAMO y fue normal.

El diagnóstico diferencial histopatológico incluye proliferaciones intravasculares como las histiocitosis, las embolías carcinomatosas y los procesos leucémicos.

Esta neoplasia presenta un curso agresivo con tasas de supervivencia a 3 años de $33 \%$, generalmente asociado a un diagnóstico erróneo o tardío en $70 \%$ de los pacientes, en ocasiones únicamente diagnosticado luego de fallecidos. Actualmente la autopsia es el examen que permite el diagnóstico hasta en $40 \%$ de los $\operatorname{casos}^{17-19}$.

No existen hasta el momento estudios controlados aleatorizados comparando tratamiento para el LI. Las recomendaciones se realizan extrapolando de la experiencia con subtipos más frecuentes de linfoma difuso de células grandes B. Todos los casos de LI se consideran diseminados por lo tanto se tratan como enfermedad avanzada. Se recomienda quimioterapia asociada del tipo del $\mathrm{R}-\mathrm{CHOP}$ en casos de inmunofenotipos compatibles con células $\mathrm{B}^{19-24}$. Si bien el trasplante autólogo de medula ósea es una opción en algunos casos (en especial jóvenes) luego de la primera remisión, en general se indica como terapia de salvataje $\mathrm{e}^{23,24}$. La terapia con R-CHOP no atraviesa la barrera hematoencefálica por lo que se recomienda terapia intratecal ya sea como profilaxis o tratamiento ${ }^{19}$.

Dada la presentación inusual de este tipo de linfoma, los criterios de remisión utilizados para otras variedades de linfoma no Hodgkin no son aplicables. Se ven mayores recaídas en pacientes con compromiso de SNC que en pacientes con compromiso cutáneo aislado ${ }^{20,21}$.

Como conclusión, creemos que debería sospecharse ante un síndrome general, fiebre, afectación cutánea o neurológica, con sintomatología multiorgánica, inflamatoria y acompañados de valores muy elevados de LDH y beta 2-microglobulina. En estos casos deberíamos plantearnos realizar una biopsia de piel que incluya tejido celular subcutáneo, aunque el paciente no presente lesiones cutáneas, para conseguir un diagnóstico precoz.

\section{Referencias}

1. Murase T, Nakamura S, Kawauchi K, Matsuzaki H, Sakai C, Inaba T, et al. An Asian variant of intravascular large B-cell lymphoma: clinical, pathological and cytogenetic approaches to diffuse large B-cell lymphoma associated with haemophagocytic syndrome. Br J Haematol 2000; 111: 826-34.

2. Ferreri AJ, Campo E, Seymour JF, Willemze R, Ilariucci F, Ambrosetti A, et al. Intravascular lymphoma: clinical presentation, natural history, management and prognostic factors in a series of 38 cases, with special emphasis on the 'cutaneous variant'. Br J Haematol 2004; 127: 173-83. Review.

3. Shimada K, Matsue K, Yamamoto K, Murase T, Ichikawa $\mathrm{N}$, Okamoto $\mathrm{M}$, et al. Retrospective analysis of intravascular large B-cell lymphoma treated with rituximab-containing chemotherapy as reported by the IVL study group in Japan. J Clin Oncol 2008; 26: 3189-95.

4. Pfleger L, Tappeiner J. [On the recognition of systematized endotheliomatosis of the cutaneous blood vessels (reticuloendotheliosis?]. Hautarzt 1959; 10: 359-63.

5. Thomas CA, Guileyardo JM, Krause JR. An intravascular lymphoma with extravascular tendencies. Proc (Bayl Univ Med Cent) 2014; 27: 341-3.

6. Chapin JE, Davis LE, Kornfeld M, Mandler RN. Neurologic manifestations of intravascular lymphomatosis. Acta Neurol Scand 1995; 91: 494-9.

7. Detsky ME, Chiu L, Shandling MR, Sproule ME, Ursell MR. Clinical problem-solving. Heading down the wrong path. N Engl J Med 2006; 355: 67-74.

8. Lu PH, Kuo TT, Yu KH, Lin TL, Chang SL, Yang CH. Intravascular large B-cell lymphoma presenting in subcutaneous fat tissue and simulating panniculitis clinically. Int J Dermatol 2009; 48: 1349-52.

9. Zuckerman D, Seliem R, Hocheberg E. Intravascular lymphoma: The Oncologist "great imitator". Oncologist 2006; 11: 496-502.

10. Baehring JM, Longtine J, Hochberg FH. A new approach to the diagnosis and treatment of intravascular lymphoma. J Neurooncol 2003; 61: 237-48.

11. Gill S, Melosky B, Haley L, ChanYan C. Use of random 
skin biopsy to diagnose intravascular lymphoma presenting as fever of unknown origin. Am J Med 2003; 114: 56-8.

12. Kidson-Gerber G, Bosco A, Maccallum S, Dunkley S. Two cases of intravascular lymphoma: highlighting the diagnostic difficulties in pyrexia of unknown origin. Intern Med J 2005; 35: 569-70.

13. Kim WR, Ludwig J, Lindor KD. Variant forms of cholestatic diseases involving small bile ducts in adults (Review). Am J Gastroenterol 2000; 95: 1130-8.

14. Abe H, Kamimura K, Mamizu M, Shibazaki Y, Ishiguro T, Katada S, et al. Early diagnosis of hepatic intravascular lymphoma: a case report and literature review. Intern Med 2014; 53: 587-93.

15. Tapia OE, Jiménez PP. Linfoma intravascular de células B grandes: hallazgos clínicos y morfológicos en un caso con desenlace fatal. Rev Med Chile 2012; 140: 225-30.

16. Chen Y, Ding C, Lin Q, Yang K, Li Y, Chen S. Primary intravascular large B-cell lymphoma of the lung: a review and case report. J Thorac Dis 2014; 6: E242-5.

17. Murase T, Yamaguchi M, Suzuki R, Okamoto M, Sato Y, Tamaru J, et al. Intravascular large B-cell lymphoma (IVLBCL): a clinicopathologic study of 96 cases with special reference to the immunophenotypic heterogeneity of CD5. Blood 2007; 109: 478-85.
18. Song DE, Lee MW, Ryu MH, Kang DW, Kim SJ, Huh J. Intravascular large cell lymphoma of the natural killer cell type. J Clin Oncol 2007; 25: 1279-82.

19. Ponzoni M, Ferreri AJ, Campo E, Facchetti F, Mazzucchelli L, Yoshino T, et al. Definition, diagnosis, and management of intravascular large B-cell lymphoma: proposals and perspectives from an international consensus meeting. J Clin Oncol 2007; 25: 3168-73.

20. Shimada K, Murase T, Matsue K, Okamoto M, Ichikawa N, Tsukamoto N, et al. Central nervous system involvement in intravascular large B-cell lymphoma: a retrospective analysis of 109 patients. Cancer Sci 2010; 101: 1480-6.

21. Ponzoni M, Ferreri AJ. Intravascular large B cell lymphoma: widespread but not everywhere. Acta Haematol 2014; 131: 16-7.

22. García-Muñoz R, Rubio-Mediavilla S, Robles-de-Castro D, Muñoz A, Herrera-Pérez P, Rabasa P. Intravascular large B cell lymphoma. Leuk Res Rep 2014; 3: 21-3.

23. Raza M, Qayyum S, Raza S, Goorha S. Intravascular B-Cell Lymphoma: An Elusive Diagnosis Journal of Clinical Oncology 2012; 30: e144-e145.

24. Shimada K, Kinoshita T, Naoe T, Nakamura S. Presentation and management of intravascular large B-cell lymphoma. Lancet Oncol 2009; 10: 895-902. 